\title{
A PRAIRIE AQUARIUM
}

ANDY LAMB, No. $35-330$ N. Nanaimo St., Vancouver, B.C. V 5L 3J6, and JOHN E. GAWRON.

A countless number of rivers, treams, lakes and ponds throughout rairie Canada provide habitats for a myriad of fascinating freshwater rganisms. Some of these creatures, uch as the ferocious northern pike and the famous goldeye are familiar to nany prairie people. However, tumerous aquatic animals spend their ives in relative obscurity, probably known only to a handful of biologists.

In addition to freshwater habitats, ome 500 miles of Hudson Bay coastline, adds a marine element to an lleady diverse prairie fauna. Therefore, a vast spectrum of life, rom microscopic daphnia to highly ophisticated marine mammals, bound in multitudes throughout the vaters of central Canada. This entire quatic realm and its interelationships beckon for man's undertanding and compassion. A prairie quarium could provide the vehicle or transmitting this knowledge, omething central Canada richly eserves.

Canada has long recognized an ssential commitment to comprehend he complexities of the watery world. n various centres across our ominion, a number of public aquaria xist or are under construction. Vicria, Vancouver, Toronto, Montreal, uebec City, Charlottetown and lalifax are now fortunately endowed ith facilities that interpret aquatic fe to their citizens. Only a superficial lance at this list reveals an obvious bsence with regard to the prairie rovinces.

The fact that central Canada does ot as yet have a public aquatic centre an be viewed as an advantage when onsidering the implementation of ich a socio-educational establishent. Careful planning of what the initution should be, combined with a itical review of other facilities and their achievements, can result in an aquarium with immense impact. The enviable position of being able to learn from successes and failures of others is one that should be capitalized on.

Present climatic factors have exerted momentous effects upon the prairie landscape which have resulted in the creation of four biotic regions. The semi arid climate of the Great Plains provides the flat rolling habitat for a grassland flora. A rich geologic legacy provides the precambrian bedrock upon which dwell the spruce-pine forests and associated faunas of the shield region. Smallest of the four zones, the narrow coastal band known as the sub-arctic furnishes a harsh, permafrost realm where sparse groundhugging vegetation ekes out life in a short growing season. Finally, the majestic Rocky Mountain barrier with its diversity of climates supplies an abundance of alpine habitats.

Within these zones, four relatively different aquatic faunas flourish. Although not mutually exclusive, most of the freshwater organisms which dwell in one region differ significantly from those of the other three areas. Through meaningful interpretation, a prairie aquarium could provide a public focal point for participatory interest in native aquatic life.

A regional aquarium concept can instill an abiding respect and pride among prairie citizens for their aquatic heritage. The substantial coastline along Hudson Bay will undoubtedly become increasingly important with the passage of time. As a last frontier, we all recognize that the north will play a vital role in our country's future. Interestingly, the marine creatures of the north have received little attention as yet from Canadian aquaria. A tremendous opportunity exists for a prairie aquarium to present this poorly understood fauna to all 


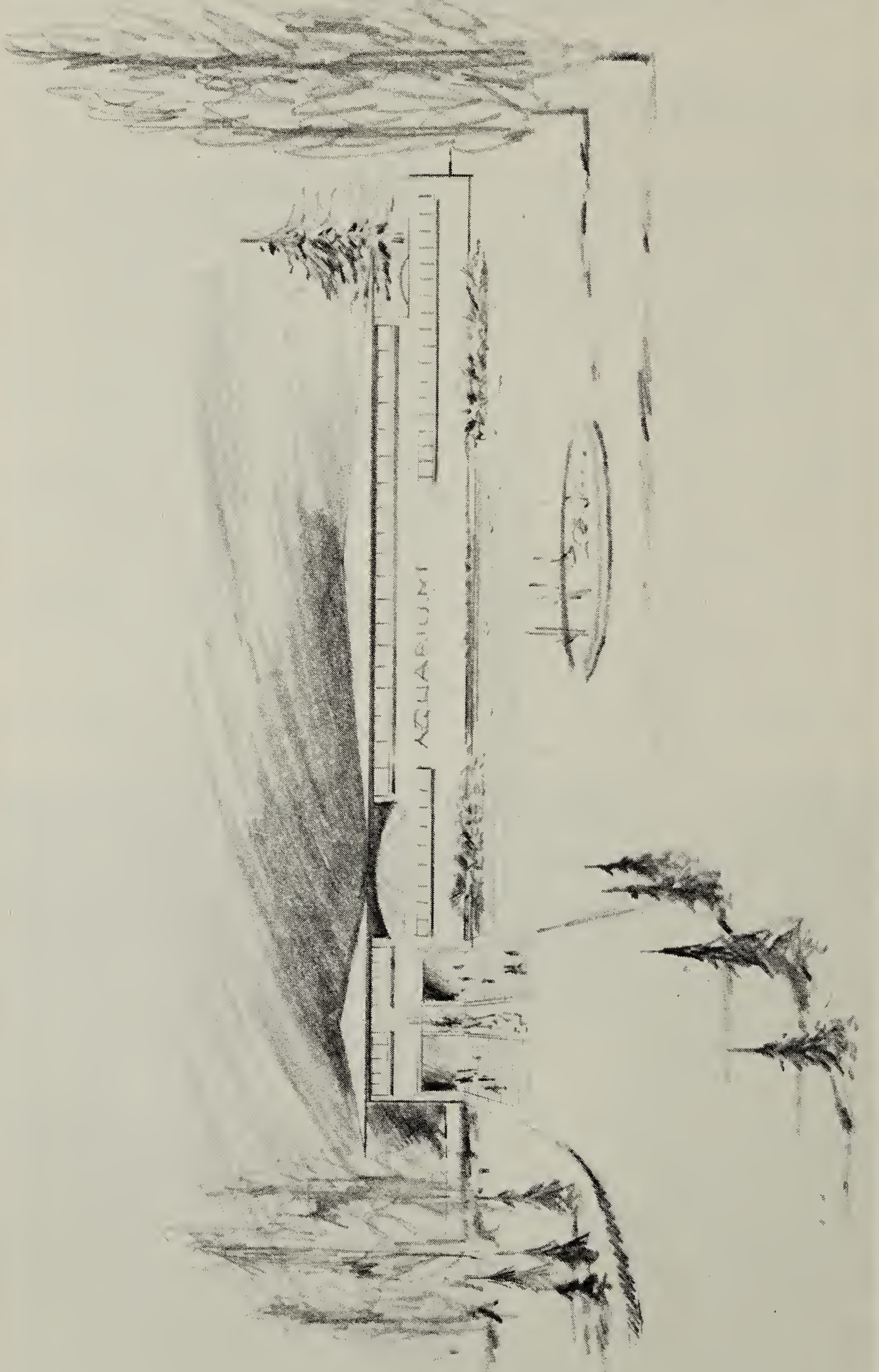




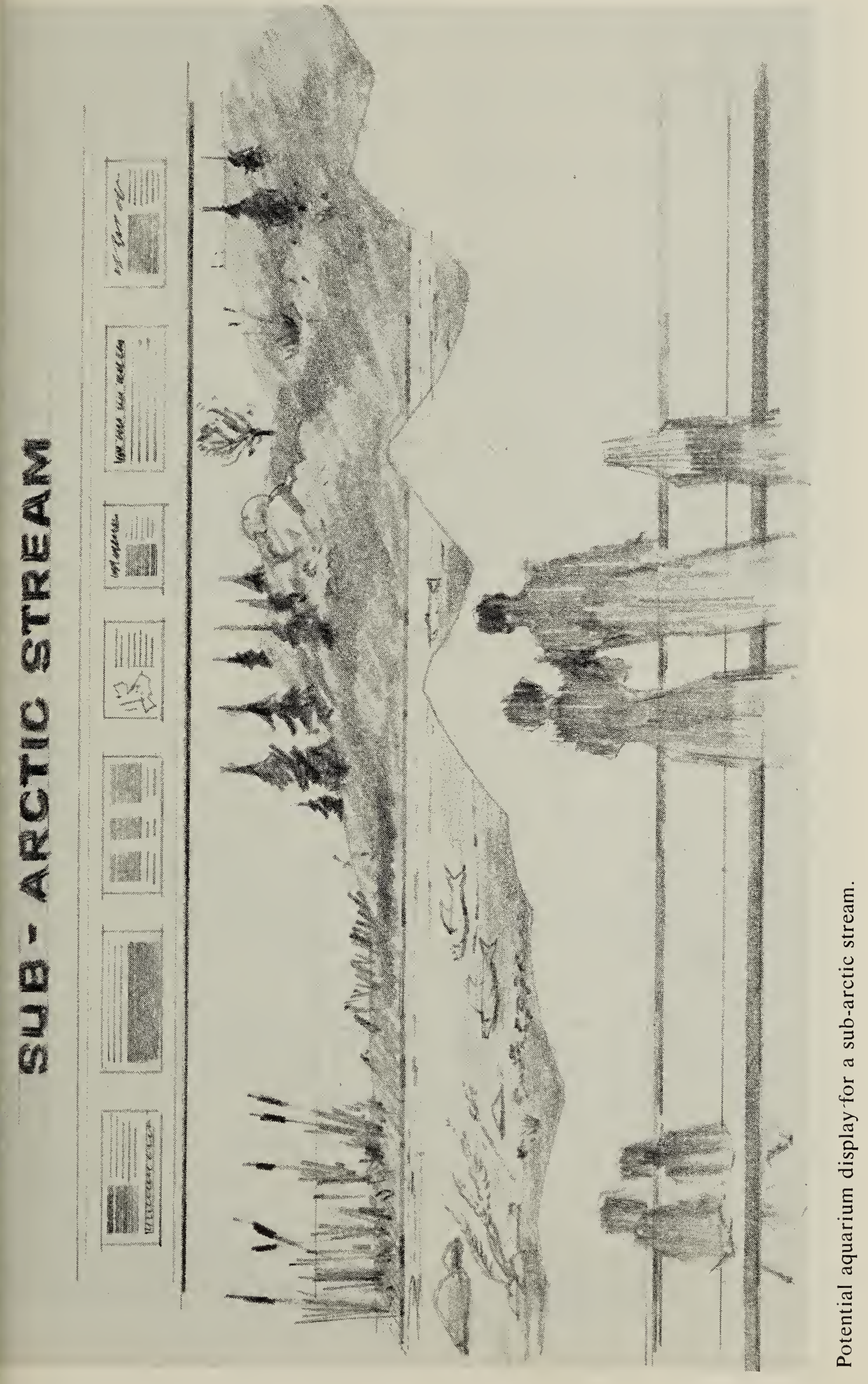


Canadians through fascinating and enlightened interpretation programs.

Fundamental to an aquarium concept, could be the all-encompassing use of the facility as a dynamic educational implement. A public aquatic centre would provide each and every one of its visitors with a thoroughly orchestrated message about the prairie aquatic heritage in a manner both educational and recreational. Having been exposed to this dual thrust, visitors will be both entertained and stimulated by his or her illustrated tour of central Canada's aquatic world. Ideally their experience will eventually culminate in a knowledgeable and enduring concern for the fragile ecology of the watery environment. This concern for the welfare of all aquatic organisms on our rapidly changing planet could be further encouraged through a public participatory aquarium.

Molded to the philosophy of a public aquarium should be the premise that as an individual, each visitor visualizes and assimilates information at a personalized rate. This concept, therefore, should be accounted for when the functional design of such an institution is being considered. However, each individual should have the opportunity to exercise a choice based upon individual needs and desires, when participating in a programmed tour through the facility. The overall recreational-educational theme of the aquarium provides a framework for specialized programs. The creation of specific agendas, catering to distinct interest groups, could be an important duty of the institution and its staff. Facilities and expertise could enable particular audiences such as school children, conservationists, anglers, commercial fishermen, aqua-culturists; photographers, and divers, to absorb and investigate material pertinent to their own fields of endeavour. As a community resource, the aquarium could encourage public participation in its activities. Through participatory memberships, interested parties could assist in providing leadership and direction for the aquarium so that it could take its rightful place in prairie culture.

Undoubtedly, the most important special-interest group to be served by an aquarium would be the future citizens of our country - the children. It is with them that the future of these provinces' aquatic domains will rest. Therefore, an aquarium in central Canada could provide an ambassadorship for the lakes, streams, ponds and seas of the region, thereby helping to ensure their future safety.

During the school year and in conjunction with regional school boards, aquarium staff could work closely with teachers to enable the facility to serve to its fullest capacity. Carefully prepared material could be made available to the schools prior to visits, enabling maximum value to be extracted from the tours.

In these days of ever mounting parental concern about the education of their children, a responsive aquarium could provide a unique opportunity for actual participation by parents in their offsping's enlightenment. Under the supervision of aquarium staff, willing adult volunteers could be thoroughly trained to take an active role as docents, personnel who provide guidance for school groups. Not only will both child and adult simultaneously benefit from this relationship, but the possibility of closing the generation gap is increased. Community involvement through the educational process is a commitment upon which such an aquarium could be founded.

To facilitate and encourage maximum use of the aquarium's educational potential, evening adult courses could be arranged, primarily during winter months. Highly qualified guest speakers, drawn from university, research institutes and museums throughout Canada's midwest, could be solicited to provide presentations in their fields of expertise. Through dialogue between aquarium staff and the public, the curricula of these lecture series would largely be determined by public interest. It is anticipated that countless 


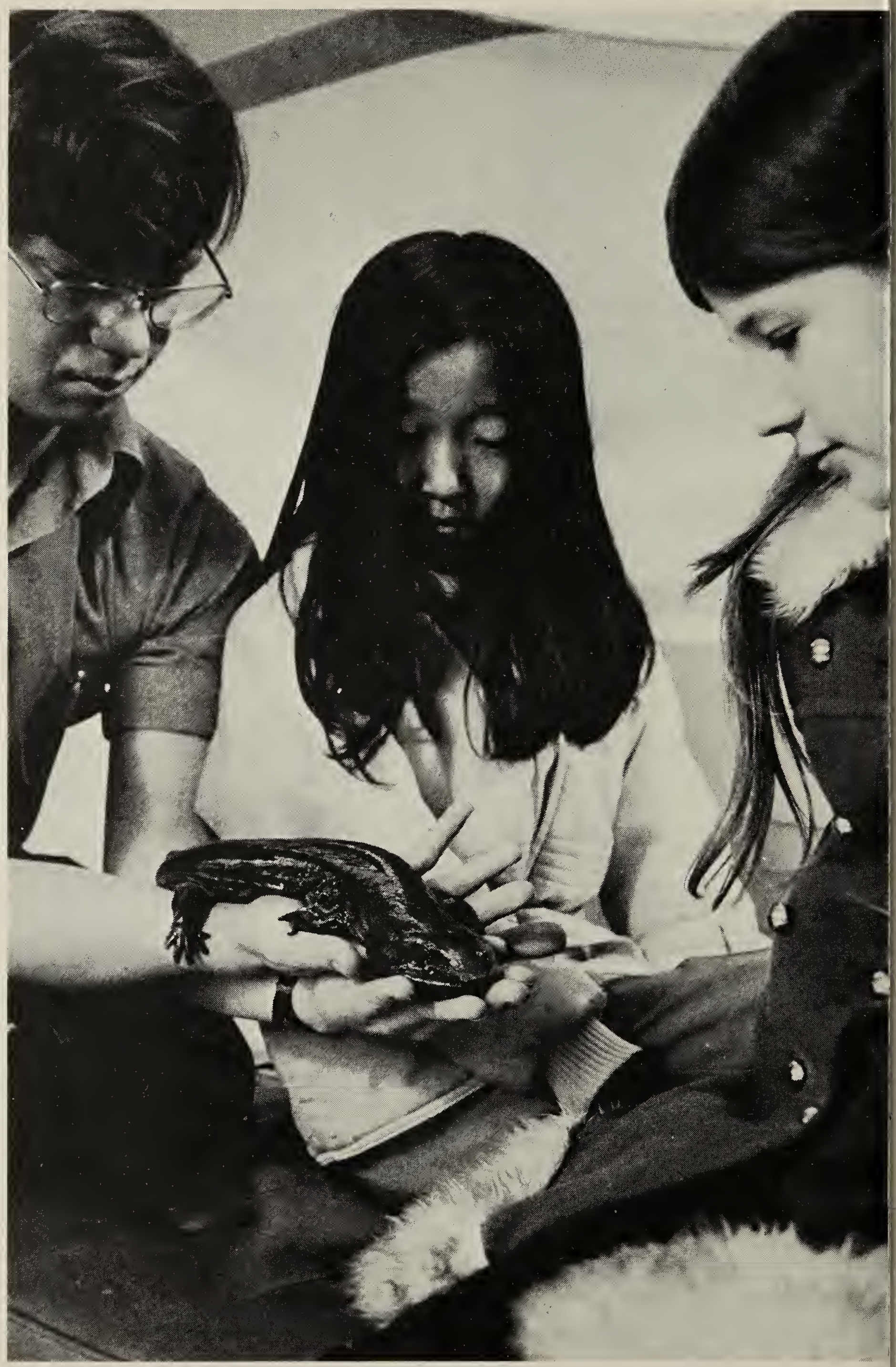

First hand experience with a salamander.

Gar Lunney 
hours of productive, enjoyable leisure time would reward citizens enrolling in such programs.

An up-to-date informed public is one that could make the best use of an aquarium and its programs. Institutions such as aquaria are involved in a continual flow of new projects and constantly changing displays. Regular bulletins about the aquarium and its activities could be distributed. In addition, a liaison between the press and the aquarium could also contribute to the public awareness. The related role of a public clearinghouse of aquatic information could be an important additional service to the people of the Prairies.

A natural, built-in dichotomy exists that would, to some degree, separate peak participation in the aquarium by tourists and local visitors. Active prairie folk make the most of their summer months by enjoying the great outdoors. It is at this time that the tourist influx reaches its maximum. In response to this different and special clientele, every effort could be focused on them in an attempt to make their visit a memorable and enjoyable one.

As a member of the economic community, a central Canadian aquarium would assume its place in the exchange of goods and services with other businesses. An aquarium would obviously require products, both commonplace and specialized, that would largely be available locally. Within the modern aquarium, it is anticipated that a retail gift shop, professionally run by competent staff, could be set up. Not only could such a facility supply revenue for a financially stable aquarium, but it could provide an opportunity for local craftsmen and writers to display their talents.

A simulated tour of the aquatic habitats of the prairies via programmed natural exhibits would be complemented greatly by modern technology. Enlightened interpretation of the organisms, facilitated by a multitude of modern audio-visual aids, would enhance the impact of the aquarium. Extensive graphics and recorded messages would serve to stimulate visitors to consider the importance of natural wetlands not only to all aquatic creatures, but also to themselves.

Upon entering the aquarium, the visitor would receive an explanatory presentation which briefly describes the concepts to be illustrated by the series of exhibits. When the visitor has completed his tour, additional information of lasting value in pamphlet form would be available. A comprehensive list of books and other literature, categorized into subject and age levels, would enable visitors who have had their interests stimulated, to delve further into the subject. A graphically potent aquarium could serve as a stimulating introduction to the aquatic world and also provide assistance to people wishing to further undertand the aquatic realm of our planet.

The primary goal of a public aquarium for the prairies could be an expose of all forms of aquatic life for the community benefit. Aside from divers, the vast majority of Canada's population is not able to relate in a first-hand manner to the aquatic creatures of the region. Through an aquarium, each animal be it a renowned sportfish, tiny aquatic insect, frog, retiring snake or friendly seal, would have its fascinating ecology realistically portrayed. The underwater viewing approach toward the organism and its element is the basic tool of an aquarium's presentation. It allows one to comprehend the creature and its environment in the most consumate way short of actual residence in the water. By bringing organisms from widely separated regions throughout central Canada and putting them in a convenient location with the added dimension of underwater viewing, an aquatic centre would provide most of the public with its only exposure to the watery environment.

An aquarium is essentially a "living" museum which displays organisms as they relate to their ecology through a semi-natural environment. Numerous 


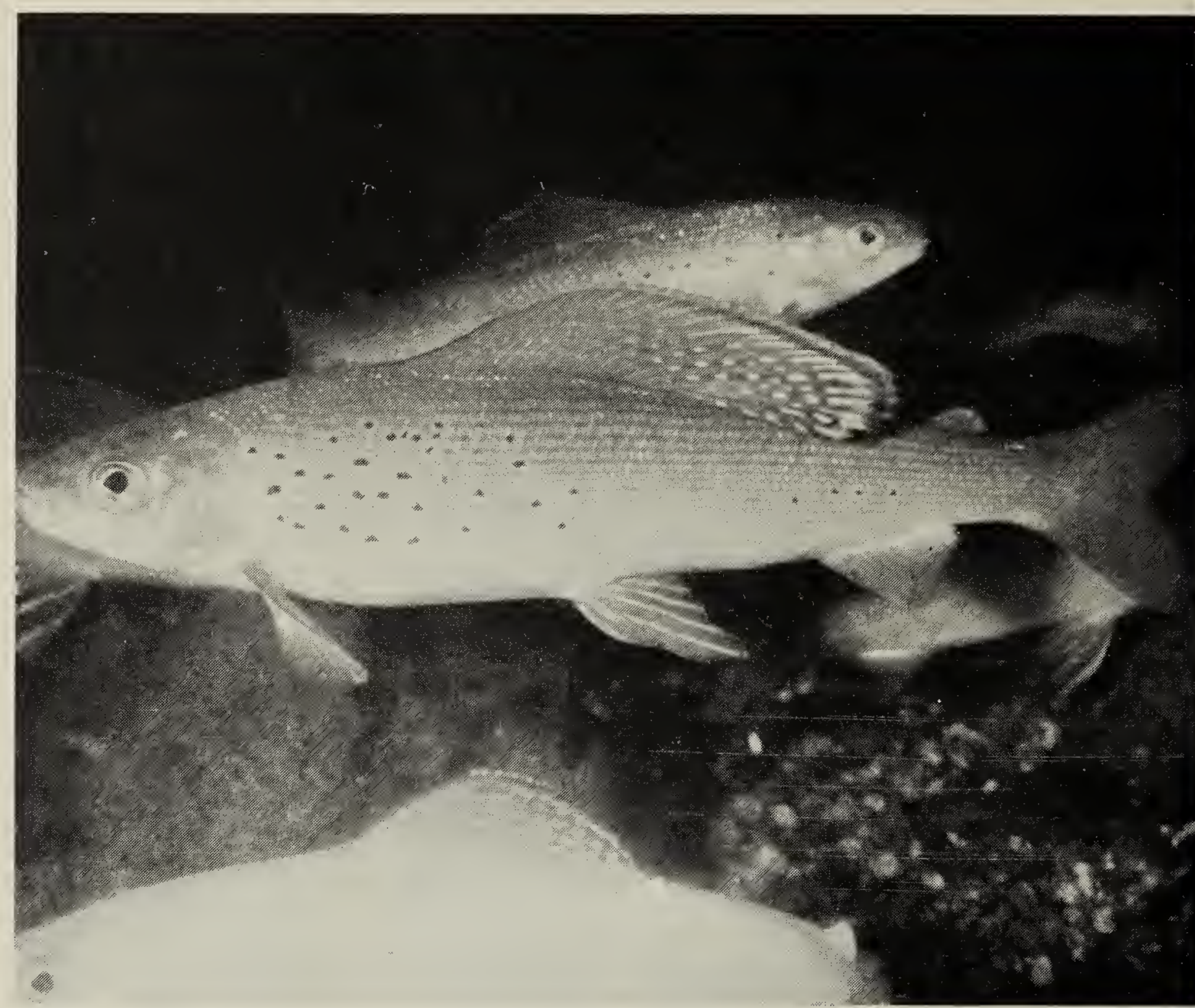

Arctic Grayling.

Phil Edgel

vital factors must be constantly monitored and directed by competent professionals to create such a living macrocosm. The prime requirement for the various exhibits is quality recycled water. This water would be obtained by an intricate filtration system, then circulated throughout the entire facility. Representative aquatic organisms would be collected and maintained in a healthy condition via various techniques of scientific husbandry. With such conditions fulfilled, visitors would be able to view living displays where the organisms would interact with their environment in a manner as closely as possible duplicating nature.
We of this generation have an immense and sobering responsibility that has been unassumingly thrust upon us. However innocently and unwillingly received, it nevertheless remains that the future of the aquatic environment must be covetously appreciated. It is time to make a commitment to these noble goals and to pursue them with the utmost haste and dedication. It is time for an enlightened citizenry to be introduced to an aquatic awareness. A contemporary aquarium could be the catalyst for such an awareness. 